\title{
A PARTICIPAÇÃO DE INSTITUIÇÕES DE ENSINO SUPERIOR PRIVADAS NA FORMAÇÃO EM SAÚDE NO BRASIL
}

\author{
THE PARTICIPATION OF PRIVATE HIGHER EDUCATION \\ INSTITUTIONS IN HEALTH TRAINING IN BRAZIL
}

\author{
LA PARTICIPACIÓN DE INSTITUCIONES DE ENSEÑANZA SUPERIOR \\ PRIVADAS EN LA FORMACIÓN EN SALUD EN BRASIL
}

Thais de Andrade Vidaurre Franco ${ }^{1}$

Mario Roberto Dal Poz ${ }^{2}$

Resumo O ensino superior brasileiro, historicamente, é marcado pela presença de instituições privadas. Durante a franca expansão ocorrida nas duas últimas décadas, o setor privado apresentou um crescimento no número de matrículas e no percentual de participação. Este artigo descreve a participação privada nas graduações da saúde no período entre 1993 e 2013. A revisão bibliográfica sobre o ensino superior brasileiro e a análise descritiva de dados secundários evidenciaram que a participação do setor privado na formação em saúde, em muitos aspectos, tem sido compatível com a dinâmica do setor de ensino superior. Na década de 1990, o crescimento do setor privado foi tendência em todas as graduações em saúde, e na maior parte dos cursos as taxas de crescimento foram maiores que a média nacional. No período entre 2003 e 2013, os cursos de Medicina, Odontologia e Serviço Social apresentaram taxas de crescimento maiores que no período anterior e os demais apresentaram uma desaceleração das taxas de crescimento; já nos cursos de Biologia, Fonoaudiologia e Terapia Ocupacional, observou-se uma redução do número de matrículas em instituições privadas.

Palavras-chave instituições de ensino superior; setor privado; recursos humanos em saúde; educação superior.
Abstract Brazilian higher education has been historically marked by the presence of private institutions. During the unhindered expansion that took place over the past two decades, the private sector presented a growth in the number of enrollments and in the percentage of participation. This article describes the private participation in the undergraduate courses in health in the period between 1993 and 2013. The review of the literature on Brazilian higher education and the descriptive analysis of the secondary data evinced that the participation of the private sector in the training in health, in many aspects, has been compatible with the dynamics of the higher education sector. In the 1990s, the growth of the private sector was a trend in all undergraduate courses in health, and, in most courses, the growth rates were higher than the national average. In the period between 2003 and 2013, the courses of Medicine, Odontology and Social Services presented growth rates that were higher than those of the preceding period, and the other courses presented a decrease in the growth rates; as for the courses of Biology, Speech and Language Therapy and Occupational Therapy, a decrease in the number of enrollments in private institutions was observed. Keywords higher education institutions; private sector; human resources in health; higher education. 


\section{Introdução}

Durante as últimas décadas, a expansão de Instituições de Ensino Superior (IESs) privadas foi observada em diversos sistemas de ensino superior de diferentes países e regiões. Em 2013, o setor privado representava 31 \% do total de matrículas do ensino superior mundial e apresentava as maiores taxas de crescimento (Altbach, Reisberg e Rumbley, 2009; Levy, 2013). O Brasil está entre os países que apresentam os maiores níveis de participação privada no ensino superior, junto com países como Indonésia, Japão, Filipinas, e Coréia do Sul (Altbach, Reisberg e Rumbley, 2009; Stromquist, 2012).

Desde a década de 1990, o ensino superior brasileiro passou por um período de crescimento exponencial do número de vagas, cursos e matrículas, bem como por uma diversificação dos tipos de instituições, modalidades de ensino e cursos. A expansão das IESs privadas, principalmente das privadas com fins lucrativos, constituiu uma das mudanças mais significativas e foi acompanhada por transformações no formato administrativo-jurídico dessas instituições (Fávero e Sguissardi, 2012). De acordo com esses autores, no período entre 1999 e 2010, o crescimento do número de matrículas no ensino superior privado ocorreu de forma extremamente desigual entre os subsetores privado não lucrativo e lucrativo, tendo o subsetor lucrativo apresentado um crescimento de $420 \%$ no total de matrículas e o subsetor não lucrativo, um decréscimo de $32,3 \%$.

A obtenção de lucro por instituições de ensino superior foi permitida com a publicação do decreto n. 2.306, de 1997, no contexto de flexibilização do marco regulatório do ensino superior promovido pela Lei de Diretrizes e Bases de 1996, durante o governo de Fernando Henrique Cardoso. Consideradas empreendimentos educacionais, as IESs privadas com fins lucrativos passaram a adotar estratégias de mercado como a profissionalização da gestão, a abertura de capital e a formação de oligopólios (Carvalho, 2013; Sguissardi, 2013). O processo de oligopolização do setor de ensino superior no Brasil tem ocorrido pela aquisição de instituições de médio ou pequeno porte em dificuldades financeiras por grandes grupos educacionais, ou então por meio de fusões que permitem o aumento dos ganhos, a atuação em novos nichos e regiões, assim como, o crescimento do número de alunos e de cursos (Carvalho, 2013).

A maioria dessas operações de aquisição e fusão no setor de ensino superior brasileiro tem sido realizada por grupos empresariais que operam capital na Bolsa de Valores de São Paulo. Para Carvalho (2013), a abertura de capital por IESs indica um processo de financeirização do setor que acarreta importantes mudanças na gestão dessas instituições, uma vez que as decisões empresariais passam a ser tomadas visando ao aumento do valor acionário e à expansão do market share ${ }^{3}$ e não necessariamente aos aspectos educacionais. 
Ainda são poucas as empresas com capital aberto atuando no campo educacional no Brasil, porém essas empresas representam um número expressivo de matrículas e cursos. Em 2014, eram IESs com capital aberto em funcionamento no Brasil: Estácio Participações, Kroton Educacional, Sistema Educacional Brasileiro Participações S.A. e GAEC Educacional S.A, e os grupos americanos Laureate International Universities e DeVry Education Group (Sécca e Leal, 2009; Tuon, 2014). Em 2014, a fusão dos grupos de educação Anhanguera e Kroton representou uma mudança significativa na composição do setor. Juntos, esses grupos educacionais passaram a $17^{\mathrm{a}}$ maior empresa em termos de valor de mercado na Bovespa (Tuon, 2014).

O Estado vem exercendo um papel importante na expansão do setor privado no ensino superior, ao adotar mecanismos diretos e indiretos de financiamento estatal a essas instituições (Salto, 2014), como isenção de impostos e contribuições por meio do Programa Universidade para Todos (Prouni), oferta de crédito educativo subsidiado pelo Fundo de Financiamento ao Estudante de Ensino Superior (Fies), e oferta de empréstimos financeiros com juros subsidiados por meio do Banco Nacional de Desenvolvimento Econômico e Social (Sécca e Leal, 2009; Taneguti, 2013).

Cabe ressaltar que a história da expansão do ensino superior privado no Brasil não começou na década de 1990. A atuação dessas instituições teve um início precoce no país, avançou durante a ditadura militar e se manteve nas décadas seguintes, inclusive pela manutenção de políticas de incentivo ao setor privado, como a isenção fiscal (Durham, 2003; Mancebo e Vale, 2013). Entre 1965 e o final da década de 1970, tanto o setor público quanto o privado se expandiram; porém, o setor privado teve um crescimento mais expressivo, alcançando uma participação de 60\% do total de matrículas (Durham, 2003; Martins, 2013). É importante notar que durante a ditadura militar o desenvolvimento de ambos os setores ocorreu em linhas divergentes. Enquanto as instituições públicas, principalmente as federais, organizaram-se em universidades e começaram a desenvolver atividades de pesquisa e extensão, a expansão das IESs privadas ocorreu por meio da ampliação de um setor empresarial que mantinha escolas isoladas, concentradas em cursos de baixo custo e menor exigência acadêmica, e para as quais a qualidade do ensino era um aspecto secundário (Durham, 2003; Mancebo e Vale, 2013).

Em 1993, 59\% das matrículas em cursos de ensino superior presenciais eram em IESs privadas (Instituto Nacional de Estudos e Pesquisas Educacionais Anísio Teixeira, 2013). Já em 2013, das 2.391 instituições de ensino superior existentes no país, apenas 301 eram públicas. As 2.090 instituições privadas eram responsáveis por $71 \%$ das 6.152 .405 matrículas, $75 \%$ dos concluintes e $84,6 \%$ das vagas oferecidas em cursos presenciais (Instituto Nacional de Estudos e Pesquisas Educacionais Anísio Teixeira, 2013). Neste mesmo ano, 
as matrículas presenciais em cursos da saúde representavam $22 \%$ do total de matrículas em IESs privadas no país, sendo que os de Enfermagem, Psicologia, Fisioterapia e Farmácia estavam entre os dez maiores cursos privados em números de matrículas (Sindicato das Mantenedoras de Ensino Superior - Semesp, 2015). A formação de profissionais para o setor da saúde está inserida no contexto do ensino superior e, como descreveu Rezende (2013), desenrola-se em um espaço de interseção no qual as instituições de ensino e as políticas para educação superior desempenham papel decisivo na definição dos níveis de oferta e dos padrões de qualidade da força de trabalho. Dessa forma, o aumento da participação privada e os processos recentes de mudança no ensino superior brasileiro, como o aumento da participação de IESs privadas lucrativas, a entrada de instituições com capital aberto no ensino superior e a presença de grandes grupos educacionais surgem como uma das faces do imbricamento público-privado que podem interferir no sistema de saúde e dessa forma exigir políticas específicas.

O processo de privatização da formação dos profissionais da saúde vem sendo destacado por importantes estudos sobre as graduações em saúde, tanto no âmbito nacional quanto internacional, os quais forneceram importantes elementos para a compreensão da formação como um todo (Pierantoni et al., 2012; Dal Poz, Pierantoni e Sábado, 2013; Dal Poz e Scheffer, 2015; Mcpake et al., 2015). No entanto, acredita-se que um olhar mais atento para o setor privado e um esforço de análise que considere também o contexto geral do ensino superior no Brasil podem contribuir para o debate já em curso.

Nesta perspectiva, o presente artigo busca reconhecer as características do setor de ensino superior privado e identificar elementos que colaborem para um melhor entendimento da dinâmica do mercado de ensino superior nos cursos da saúde, de forma a contribuir com o debate acerca dos desafios e contradições do processo de regulação da formação profissional para o setor. Neste artigo são apresentadas as principais tendências da participação de IESs privadas nos cursos da saúde entre 1993 e 2013, buscando destacar os aspectos comuns e divergentes entre as diversas graduações em saúde e o ensino superior privado em geral, assim como as especificidades de cada curso.

\section{Métodos}

Trata-se de um estudo descritivo que envolveu diversas estratégias metodológicas, tais como: revisão bibliográfica sobre o ensino superior brasileiro; o ensino superior privado e as políticas para a formação de profissionais da saúde; e a análise quantitativa sobre a participação de IESs privadas nas graduações em saúde.

Para descrever o panorama da atuação privada e identificar as tendências gerais do mercado privado de ensino superior nessas graduações, foram levantados dados referentes ao número de matrículas, cursos, vagas, ingressantes, 
concluintes e localização entre os anos de 1993 a 2013, obtidos por meio do Sistema de Informação das Graduações em Saúde (Sigras). O Sigras é uma ferramenta que processa dados sobre a Educação Superior publicados anualmente pelo Instituto Nacional de Estudos e Pesquisas Educacionais Anísio Teixeira (Inep), desenvolvido pela Rede Observatório de Recursos Humanos em Saúde/Estação de Trabalho do Instituto de Medicina Social da Universidade do Estado do Rio de Janeiro (IMS/Uerj).

A escolha do período compreendido entre os anos de 1993 a 2013 se deu diante de análises sobre a configuração do ensino superior nacional, como de Salto (2014) e Sguissard (2013), que apontam que, nesse período, ocorreram um conjunto de modificações normativas e decisões políticas que impactaram o setor, a principal delas a Lei de Diretrizes e Bases (LDB) de 1996.

Aqui, serão apontadas algumas tendências observadas na análise dos dados agregados dos cursos das 14 categorias profissionais de nível superior, definidos pela resolução n. 287, de 1998, do Conselho Nacional de Saúde, como 'categorias da saúde' (Ministério da Educação. Conselho Nacional de Saúde, 1998). O curso de Saúde Coletiva não foi considerado nesta análise, uma vez que ainda não é reconhecido pelo Conselho Nacional de Saúde e, por ser de criação recente, os dados disponibilizados pelo Inep ainda apresentam sérias inconsistências (Rede Observatório de Recursos Humanos em Saúde, 2013). Para obter as informações das graduações em saúde agregadas, sem os dados do curso de Saúde Coletiva, foram subtraídos do total apresentado no Sigras os valores referentes ao mesmo.

Posteriormente, foram analisados os dados de cada graduação em saúde separadamente, considerando dimensões como taxa de crescimento anual de cursos e matrículas, taxa de ocupação de vagas e presença de ensino a distância. Nesse momento foram usadas informações do Sigras.

Existem diversas acepções sobre os conceitos de público e privado e seus limites e, no que se refere ao ensino superior, aspectos como a natureza jurídica, enquadramento administrativo, origem do financiamento, gratuidade ou não são elementos importantes para se fazer a distinção entre as duas concepções (Dias Sobrinho, 2013). Dadas essas contradições entre o dimensionamento e a qualificação do público e do privado, neste artigo são consideradas como IESs privadas as instituições administradas por pessoas físicas ou jurídicas de direito privado, com ou sem finalidade lucrativa, reconhecendo que essa delimitação não abrange a complexidade desse fenômeno.

\section{Tendências do setor privado na formação em saúde}

Os cursos da área da saúde, de forma geral, acompanharam as tendências do ensino superior brasileiro, tanto em relação à ampliação significativa do número de instituições, vagas, matrículas e concluintes quanto ao aumento 
proporcional da participação das instituições privadas na formação desses profissionais. O Gráfico 1 mostra a evolução do total de matrículas públicas e privadas nas graduações em saúde presenciais em números absolutos e o percentual da participação privada, entre os anos de 1993 e 2013.

\section{Gráfico 1}

Evolução do número de matrículas em cursos de graduação em saúde por natureza jurídica. Brasil, 1993- 2013

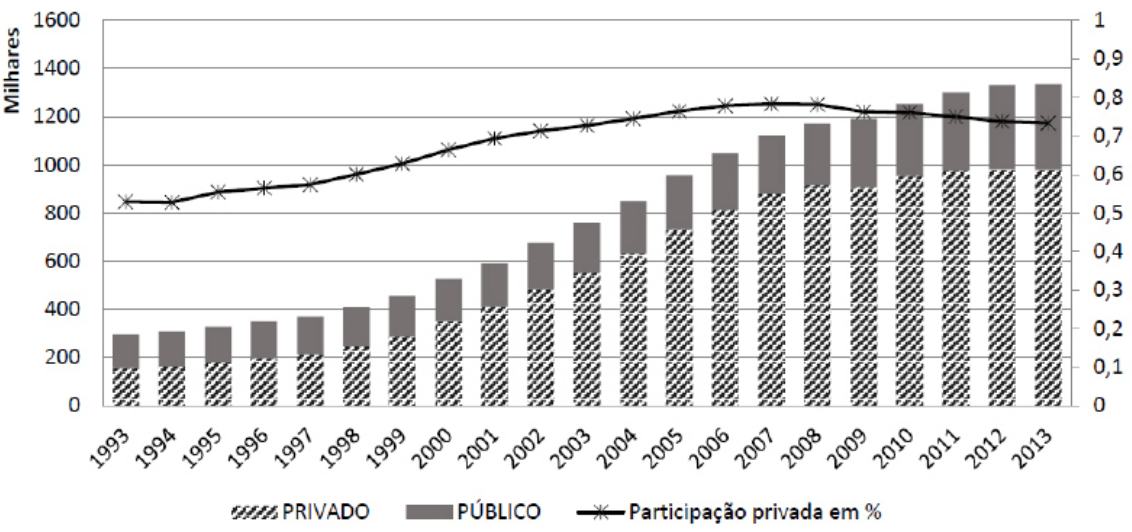

Fonte: Elaboração própria com dados do Inep/ MEC e Sigras/ObservaRH - IMS/Uerj, 2013

O número de matrículas públicas e privadas em cursos da saúde teve um acréscimo total de $372 \%$, entre 1993 e 2013. Crescimento proporcionalmente maior ao observado no ensino superior brasileiro em geral, que foi de $286 \%$ no mesmo período. O percentual de participação privada em matrículas presenciais nos cursos da saúde passou de 53\% em 1993, alcançando um pico de $78 \%$ entre 2006 e 2008, para $73 \%$ em 2013. A redução do percentual de participação das IESs privadas entre os anos de 2008 e 2013 ocorreu em um contexto de redução da taxa de crescimento do setor privado e de aumento do número de matrículas em IESs públicas, como podemos observar no Gráfico 2. Essa expansão de matrículas públicas pode guardar relação com a implementação, em 2007, do Programa de Apoio a Planos de Reestruturação e Expansão das Universidades Federais (Reuni) que, entre outras ações, incluiu o incentivo à criação de novas vagas e cursos em instituições federais de ensino superior (Corbucci, 2014). 
Gráfico 2

Evolução do número total de matrículas e variação anual em cursos presenciais em cursos de graduação em saúde

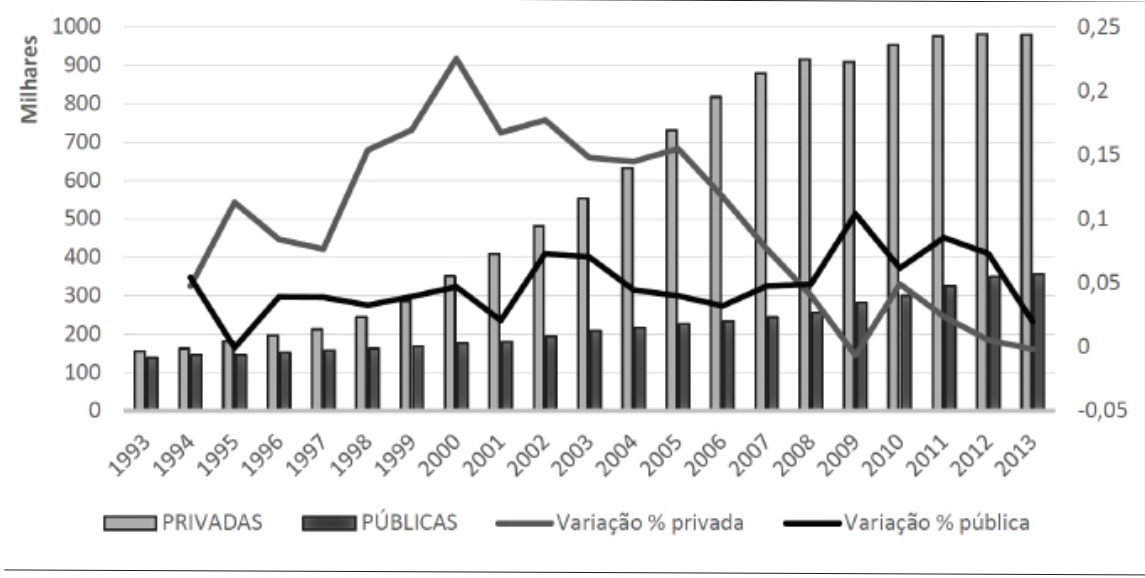

Fonte: Elaboração própria com dados do Inep/ MEC e Sigras/ObservaRH - IMS/Uerj, 2013

Um aumento expressivo no número total de cursos da saúde também foi observado no período. O total passou de 955, em 1993, com $51 \%$ de participação privada, para 6.199 em 2013, com a participação privada em torno de $72 \%$ (Gráfico 3). Esse crescimento ocorreu de forma mais intensa no período imediatamente após a publicação da LDB, em 1996. Entre 1997 e 1998, a variação anual do número de cursos da saúde privados alcançou 26,2\%. Desde 2004, ocorreu uma desaceleração da abertura de novos cursos da saúde de forma geral.

\section{Gráfico 3}

Número de cursos de graduação em saúde segundo natureza jurídica e taxa de crescimento anual em IESs privadas. Brasil, 1993-2013

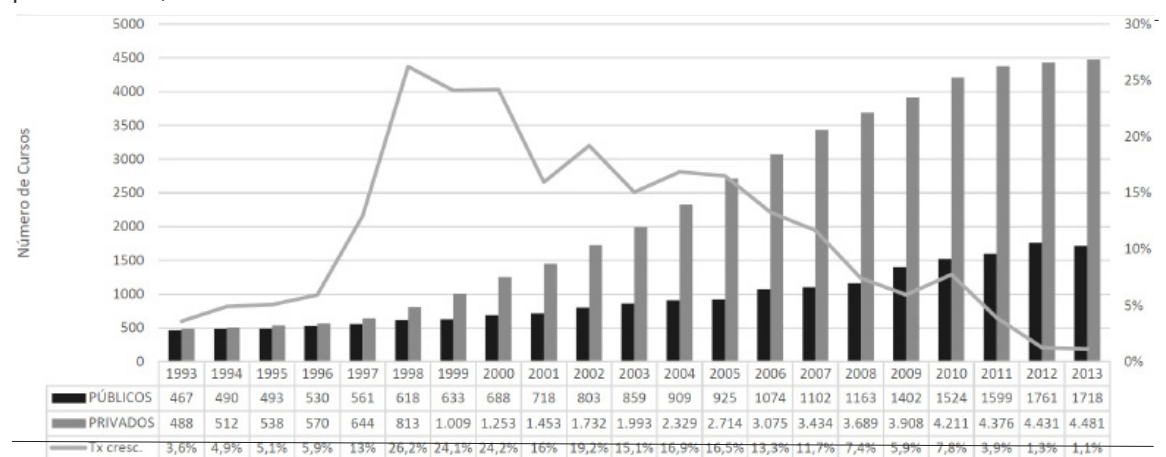

Fonte: Elaboração própria com dados do Inep/ MEC e Sigras/ObservaRH - IMS/Uerj, 2013

Historicamente, a oferta de cursos da saúde privados, assim como do ensino privado em geral, apresenta concentração nas regiões Sul e Sudeste. De 
acordo com Corbucci (2007), tal concentração se dá, dentre outros fatores, pela alta concentração populacional e pela maior renda per capita dessas regiões, características que conferem maior rentabilidade ao mercado de ensino superior. Em 2013, enquanto 53\% dos cursos da saúde privados se concentravam na região Sudeste, apenas $28 \%$ dos cursos públicos estavam nesta mesma região.

Apesar da manutenção de importantes distorções entre as regiões, de 1993 a 2013, observa-se uma tendência à desconcentração da oferta de cursos privados, caracterizada por um aumento da participação relativa das regiões Norte e Nordeste no número total. Em 1993, 66\% desses estavam no Sudeste; já em 2013, o percentual na região foi de 53\%. Nesse período, as maiores taxas de crescimento proporcional foram observadas nas regiões Norte $(5.060 \%)$, Nordeste $(2.170 \%)$ e Centro-Oeste $(1.894 \%)$, fato que pode, em parte, ser explicado pelos baixos níveis de oferta de cursos de nível superior nestas três regiões no início do período analisado.

O crescimento privado foi maior do que o observado no setor público nas cinco regiões do país. Se, no início da década de 1990, o setor privado era predominante apenas nas regiões Sul e Sudeste, onde representavam respectivamente $51 \%$ e $65 \%$ do total de cursos da saúde, em 2013, o percentual daqueles oferecidos pelo setor privado nas graduações da saúde era maior que o percentual público em todas as regiões, variando de $59 \%$ no Nordeste a $83 \%$ no Sudeste. A evolução da participação pública e privada por região pode ser observada na Tabela 1.

Tabela 1

Número de cursos da saúde por natureza jurídica; 1993, 2003 e 2013, Brasil

\begin{tabular}{|c|c|c|c|c|c|c|c|c|c|c|c|c|}
\hline \multirow[b]{3}{*}{ Região } & \multicolumn{4}{|c|}{1993} & \multicolumn{4}{|c|}{2003} & \multicolumn{4}{|c|}{2013} \\
\hline & \multicolumn{2}{|c|}{ Públicos } & \multicolumn{2}{|c|}{ Privados } & \multicolumn{2}{|c|}{ Públicos } & \multicolumn{2}{|c|}{ Privados } & \multicolumn{2}{|c|}{ Públicos } & \multicolumn{2}{|c|}{ Privados } \\
\hline & $\mathbf{n}$ & $\%$ & $\mathbf{n}$ & $\%$ & $\mathbf{n}$ & $\%$ & $\mathbf{n}$ & $\%$ & $\mathbf{n}$ & $\%$ & $\mathbf{n}$ & $\%$ \\
\hline Norte & 36 & 86 & 6 & 14 & 72 & 49 & 74 & 51 & 164 & 39 & 253 & 61 \\
\hline Centro-oeste & 42 & 65 & 23 & 35 & 79 & 37 & 133 & 63 & 168 & 31 & 377 & 69 \\
\hline Sul & 99 & 50 & 101 & 51 & 163 & 27 & 437 & 73 & 399 & 35 & 743 & 65 \\
\hline Sudeste & 174 & 35 & 322 & 65 & 257 & 17 & 1.216 & 83 & 489 & 17 & 2.390 & 83 \\
\hline Nordeste & 116 & 76 & 36 & 24 & 293 & 66 & 150 & 34 & 501 & 41 & 716 & 59 \\
\hline Brasil & 467 & 49 & 488 & 51 & 864 & 30 & 2.010 & 70 & 1.721 & 28 & 4.479 & 72 \\
\hline
\end{tabular}

\section{Participação privada por curso}

Embora a ampliação da participação de instituições privadas se apresente como tendência predominante no período analisado, a dinâmica do mercado de ensino superior privado não é homogênea. A Tabela 2 apresenta o número de matrículas em IESs privadas e o percentual de participação correspondente nos anos de 1993, 2003 e 2013, assim como a variação percentual de matrículas entre os anos de 1993 a 2003 e de 2003 a 2013, para cada curso da 
saúde. Nesta tabela ficam evidentes as diferenças entre eles, tanto em relação às dimensões do setor privado quanto ao seu desenvolvimento nas duas últimas décadas.

\section{Tabela 2}

Número de matrículas em IESs privadas, percentual da participação privada e percentual de crescimento, por curso, 1993, 2003 e 2013, Brasil.

\begin{tabular}{|c|c|c|c|c|c|c|c|c|}
\hline \multirow{2}{*}{ Curso } & \multicolumn{2}{|l|}{1993} & \multicolumn{2}{|l|}{2003} & \multicolumn{2}{|l|}{2013} & \multirow{2}{*}{$\begin{array}{l}1993- \\
2003 \\
(\Delta \%)\end{array}$} & \multirow{2}{*}{$\begin{array}{l}2003- \\
2013 \\
(\Delta \%)\end{array}$} \\
\hline & Matrículas & $\%$ & Matrículas & $\%$ & Matrículas & $\%$ & & \\
\hline Medicina & 17.444 & 36,8 & 28.559 & 46,9 & 66.336 & 59,3 & 64 & 132 \\
\hline Odontologia & 18.103 & 54,2 & 31.128 & 66,3 & 56.415 & 72,0 & 72 & 81 \\
\hline Fonoaudiologia & 6.415 & 88,4 & 12.304 & 88,1 & 6.190 & 61,8 & 92 & -50 \\
\hline Psicologia & 37.980 & 78,7 & 75.193 & 83,2 & 153.273 & 85,2 & 98 & 104 \\
\hline Serviço Social & 9.724 & 52,4 & 20.256 & 63,3 & 59.972 & 75,8 & 108 & 196 \\
\hline Terapia Ocup. & 1.607 & 68,6 & 5.991 & 82,9 & 1.994 & 33,3 & 273 & -67 \\
\hline Ed. Física & 18.868 & 52,1 & 86.315 & 74,0 & 138.024 & 73,7 & 357 & 60 \\
\hline Biologia & 9.735 & 43,9 & 49.507 & 59,0 & 42.366 & 38,6 & 409 & -14 \\
\hline Farmácia & 7.209 & 38,0 & 38.505 & 70,9 & 74.447 & 74,6 & 434 & 93 \\
\hline Veterinária & 3.758 & 29,0 & 20.322 & 60,8 & 38.271 & 63,7 & 441 & 88 \\
\hline Nutrição & 4.553 & 49,2 & 25.941 & 79,7 & 59351 & 77,6 & 470 & 129 \\
\hline Enfermagem & 9.688 & 39,6 & 71.316 & 77,4 & 194.096 & 84,5 & 636 & 172 \\
\hline Fisioterapia & 10.698 & 81,5 & 81.030 & 91,6 & 96.070 & 88,0 & 657 & 19 \\
\hline Biomedicina & $60^{4}$ & 100,0 & 5.135 & 90,8 & 38.293 & 90,4 & 8.458 & 646 \\
\hline
\end{tabular}

Alguns cursos, já no início da década de 1990, antes mesmo das mudanças instituídas pela LDB de 1996, apresentavam uma parcela significativa das matrículas em instituições privadas. Como é possível observar na Tabela 2, em 1993, as IESs privadas respondiam por mais da metade das matrículas de Fonoaudiologia, Serviço Social, Educação Física, Odontologia, Terapia Ocupacional, Psicologia e Fisioterapia. Nesse mesmo ano, os cursos de Medicina Veterinária, Medicina, Farmácia e Enfermagem apresentavam os menores percentuais de participação privada.

Quando comparados o crescimento do setor no período de 1993 a 2003 com o de 2003 a 2013, observam-se importantes diferenças. Entre 1993 e 2003, o setor privado apresentou crescimento tanto do número absoluto de matrículas quanto de sua participação proporcional em todas as graduações em saúde. Os cursos de Biomedicina ${ }^{5}$, Fisioterapia, Enfermagem, Nutrição, Veterinária, Farmácia, Biologia, Educação Física e Terapia Ocupacional apresentaram variações consideravelmente maiores do que a apresentada pela média nacional do setor privado para o mesmo período (192\%). 
Em alguns desses cursos, o setor privado atingiu variações anuais expressivas, alcançando, em determinados anos, percentuais de crescimento próximos a 50\%. Como foi o caso de Enfermagem que, no ano de 2002, apresentou uma variação percentual do número de matrículas privadas de $47 \%$ em relação ao ano anterior, e de Biologia que, entre os anos 1999 e 2000, apresentou um crescimento de $51 \%$.

Entre 1993 e 2003, os cursos de Medicina, Odontologia, Fonoaudiologia, Psicologia e Serviço Social apresentaram variações menores do que o crescimento médio do setor. O de Medicina foi o único que, em 2003, ainda era predominantemente público.

Esse quadro de crescimento irrestrito do setor não se repetiu entre os anos de 2003 e 2013. Com exceção das graduações em Medicina, Odontologia, Serviço Social e Psicologia, todos os outros cursos da saúde apresentaram uma desaceleração das taxas de crescimento de matrículas privadas e, em alguns casos, decréscimo do número de matrículas. Nesse período, é possível encontrar três diferentes tendências na participação privada.

Em 50\% dos cursos da saúde, o setor privado seguiu apresentando crescimento tanto do número total de matrículas quanto de seu percentual de participação no setor, o que indica que as taxas de crescimento de matrículas no setor privado foram maiores do que as observadas no setor público no mesmo período. Nesse grupo estão as graduações em Medicina, Serviço Social, Medicina Veterinária, Farmácia, Enfermagem, Odontologia e Psicologia. Nos cursos de Veterinária, Farmácia e Enfermagem, o setor privado apresentou variações consideravelmente menores do que as apresentadas na década anterior e vêm apresentando uma tendência de queda do número de matrículas.

Nos cursos de Educação Física, Fisioterapia, Biomedicina e Nutrição, ainda que o setor privado tenha apresentado crescimento absoluto do número de matrículas, o percentual de participação privada foi menor do que o observado no ano de 2003. Podemos afirmar que o declínio proporcional do setor privado nesses cursos, ou seja, a redução de seu market share ${ }^{3}$, resultou da combinação da desaceleração das taxas de crescimento de matrículas no setor privado com o crescimento do setor público, o que parece guardar relação, como mencionado anteriormente, com a introdução de uma política pública para expansão de instituições e vagas no ensino superior público após 2007, o Reuni.

A terceira tendência observada foi a de retração do setor privado, caracterizada pela redução, tanto em termos absolutos quanto proporcionais, do número de matrículas. Essa tendência foi notada nos cursos de Biologia, Fonoaudiologia e Terapia Ocupacional, que apresentaram entre 2003 e 2013 uma redução do número de matrículas em IESs privadas de 14\%,50\% e $67 \%$, respectivamente. 


\section{Taxa de ocupação de vagas e relação candidato/vaga por curso}

O aumento do número de vagas privadas não foi acompanhado por um aumento proporcional do número de ingressantes, como é possível observar no Gráfico 4. A desproporção entre vagas e ingressos indica a existência de vagas ociosas e ocorreu de forma mais acentuada depois de 2004. Até o ano de 2003, a taxa de ocupação de vagas nos cursos da saúde variou entre $80 \%$ e $90 \%$. Em 2004, o percentual de vagas ocupadas passou para $74 \%$ e seguiu caindo nos anos subsequentes, alcançando o menor valor (51\%) entre 2009 e 2010, anos em que ocorreu uma redução significativa do número de ingressantes. Em 2013, o percentual de vagas ocupadas se manteve baixo (58\%).

\section{Gráfico 4}

Ingressos, concluintes e vagas de graduação em saúde em instituições privadas. Brasil, 1991-2013

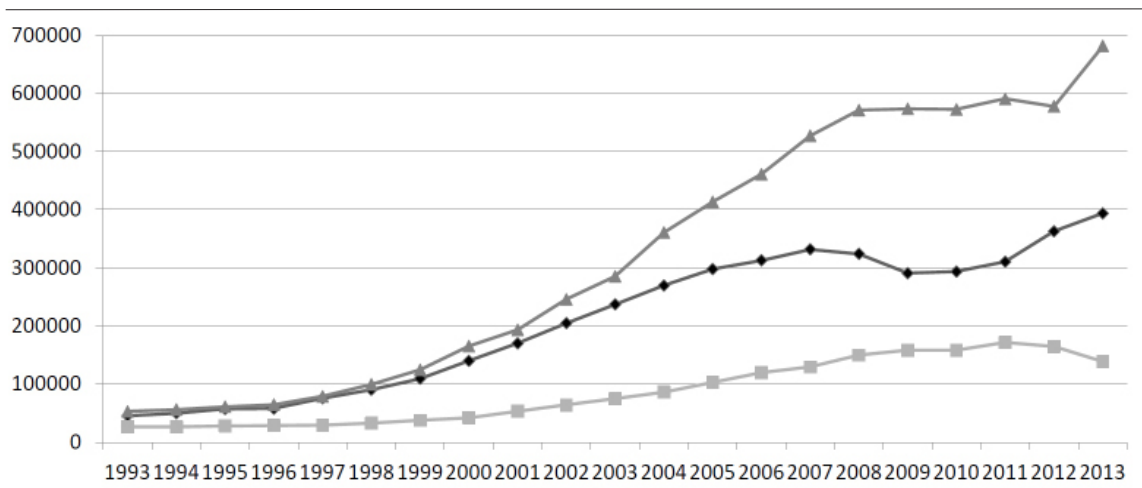

$\because$ INGRESSOS - CONCLUINTES $\because$ VAGAS

Fonte: Elaboração própria com dados do Inep/ MEC e Sigras/ObservaRH - IMS/Uerj, 2013

A ociosidade de vagas em IESs privadas é um aspecto apontado na literatura sobre ensino superior privado no país (Sécca e Leal, 2009; Taneguti, 2013; Corbucci, 2014). De acordo com Corbucci (2007), no período entre 1990 e 2005, foi observado um aumento significativo do percentual de vagas privadas não preenchidas (de 19\% para 47\%). Em 2013, 49\% das vagas em cursos presenciais ofertadas por IESs privadas não foram preenchidas, resultando em uma taxa de ocupação de apenas $51 \%$, consideravelmente inferior à taxa de ocupação de vagas públicas que, no mesmo ano, alcançou $87 \%$.

A manutenção de um elevado quantitativo de vagas iniciais é apontada pela literatura como uma prática corriqueira entre IESs privadas como uma solução para o problema dos altos índices de evasão e a perda significativa de receita resultante (Schwartzman e Schwartzman, 2002; Corbucci, 2007). De acordo com esses autores, as altas taxas de vagas ociosas são, na verdade, vagas solicitadas pela mantenedora para expansões futuras ou para proteção de 
eventuais mudanças nas regras estabelecidas que signifiquem um enrijecimento do processo de autorização e reconhecimento. Porém, mesmo considerando a existência de um percentual de vagas fictício, a oferta de vagas privadas cresceu mais rapidamente que a demanda, o que favoreceu o surgimento de uma "enorme capacidade ociosa" (Schwartzman e Schwartzman, 2002, p. 20).

Cada graduação em saúde apresenta uma relação entre o número de vagas oferecidas por cursos, taxas de ocupação e evasão diferentes. A taxa de ocupação das vagas em cursos da saúde é notadamente mais baixa nas IESs privadas do que nas IESs públicas, assim como observado para o ensino superior em geral. A partir de 2005, observa-se uma redução da taxa de ocupação também das vagas públicas em alguns cursos da saúde que, até esse ano, não apresentavam vagas ociosas. São eles: Fisioterapia, Educação Física, Biologia, Nutrição, Enfermagem, Farmácia e Serviço Social.

Com exceção do curso de Medicina, que, durante todo o período apresentou número de ingressos maior do que o número de vagas em IESs privadas, de forma geral, desde o ano de 2003, observa-se um aumento progressivo da proporção de vagas ociosas em cursos da saúde privados. Em 2013, as menores taxas de ocupação foram observadas para as graduações em Terapia Ocupacional (15\%), Biologia (30\%) e Fonoaudiologia (38\%). Psicologia, Enfermagem, Nutrição, Farmácia, Biomedicina, Educação Física e Serviço Social apresentaram taxas de ocupação entre $50 \%$ e $56 \%$, menores que a média do setor para o mesmo ano. Depois de 2010, observa-se uma tendência à redução do número de vagas ociosas nos cursos de Odontologia (99\%) e Medicina Veterinária (81\%), que, junto com o de Medicina (105\%), apresentaram taxas de ocupação em 2013 maiores do que a média nacional.

O aumento do número de vagas ociosas em determinados cursos também pode guardar relação com a redução da demanda por ingresso. A relação candidato/vaga no setor privado é historicamente menor que no púbico. Em 2013, enquanto a média para as IESs públicas era de 13,8, nas IESs privadas era de apenas 1,6 (Inep, 2013). A concorrência para ingresso nos cursos da saúde, de forma geral, foi muito próxima à média observada no setor, como podemos ver na Tabela 3.

Durante todo o período analisado, a relação candidato/vaga para Medicina foi significativamente maior do que nos outros cursos, chegando a apresentar uma concorrência nove vezes maior que Odontologia, o segundo curso da saúde mais concorrido em IESs privadas. E ainda que, a partir do início dos anos 2000, tenha ocorrido um decréscimo também na concorrência para Medicina em IESs privadas, após 2008, ocorreu um aumento significativo, quando alcançou patamares maiores do que os observados em 2003, mesmo que o número de vagas no período tenha apresentado um crescimento de aproximadamente $100 \%$. 
Os cursos de Terapia Ocupacional, Fonoaudiologia e Biologia apresentaram as menores relações candidato/vaga em todo o período. Desde 2007, eles têm apresentado número de candidatos menor do que a oferta, o que contribui para o alto índice de vagas ociosas observadas. A começar de 2010, a demanda para ingresso em Odontologia tem apresentado crescimento, contribuindo para a redução de vagas ociosas neste curso.

Tabela 3

Relação candidato/vaga para os cursos da saúde em IESs privadas e média nacional, 2003-2013

\begin{tabular}{|c|c|c|c|c|c|c|c|c|c|c|c|c|c|}
\hline Ano & 1993 & 1998 & 2003 & 2004 & 2005 & 2006 & 2007 & 2008 & 2009 & 2010 & 2011 & 2012 & 2013 \\
\hline Brasil & 2,4 & 2,2 & 1,5 & 1,3 & 1,3 & 1,2 & 1,1 & 1,1 & 1,3 & 1,2 & 1,5 & 1,6 & 1,6 \\
\hline $\begin{array}{l}\text { Terapia } \\
\text { Ocup. }\end{array}$ & 1,1 & 1,6 & 1,1 & 1,0 & 0,9 & 0,8 & 0,6 & 0,4 & 0,7 & 0,8 & 0,8 & 0,7 & 0,6 \\
\hline Biologia & 1,1 & 1,4 & 1,6 & 1,4 & 1,4 & 1,2 & 1,1 & 1,0 & 0,9 & 0,9 & 0,9 & 0,8 & 0,8 \\
\hline $\begin{array}{l}\text { Fonoau- } \\
\text { diologia }\end{array}$ & 1,8 & 1,7 & 0,9 & 0,9 & 0,9 & 0,8 & 0,7 & 0,5 & 0,7 & 0,8 & 0,7 & 0,8 & 1,0 \\
\hline Farmácia & 3,0 & 2,2 & 1,9 & 1,7 & 1,6 & 1,5 & 1,2 & 1,1 & 1,2 & 1,2 & 1,2 & 1,3 & 1,2 \\
\hline Ed. Física & 1,4 & 1,6 & 1,7 & 1,7 & 1,5 & 1,4 & 1,2 & 1,1 & 1,1 & 1,0 & 1,1 & 1,1 & 1,3 \\
\hline $\begin{array}{l}\text { Serviço } \\
\text { social }\end{array}$ & 1,2 & 1,6 & 1,8 & 1,6 & 1,5 & 1,7 & 1,3 & 1,2 & 1,4 & 1,4 & 1,5 & 1,5 & 1,4 \\
\hline Nutrição & 1,5 & 1,9 & 2,0 & 1,4 & 1,4 & 1,3 & 1,1 & 1,0 & 1,5 & 1,3 & 1,3 & 1,7 & 1,5 \\
\hline $\begin{array}{l}\text { Enfer- } \\
\text { magem }\end{array}$ & 2,6 & 2,3 & 2,5 & 2,1 & 1,9 & 1,7 & 1,5 & 1,4 & 1,5 & 1,5 & 1,6 & 1,8 & 1,6 \\
\hline $\begin{array}{l}\text { Fisio- } \\
\text { terapia }\end{array}$ & 3,1 & 3,1 & 2,1 & 1,6 & 1,5 & 1,3 & 1,1 & 1,1 & 1,2 & 1,1 & 1,4 & 1,6 & 1,6 \\
\hline $\begin{array}{l}\text { Biome- } \\
\text { dicina }\end{array}$ & - & 1,6 & 2,0 & 1,6 & 1,6 & 1,3 & 1,0 & 1,0 & 1,3 & 1,2 & 1,4 & 1,5 & 1,7 \\
\hline $\begin{array}{l}\text { Psicolo- } \\
\text { gia }\end{array}$ & 2,0 & 2,4 & 1,8 & 1,4 & 1,3 & 1,2 & 1,1 & 1,1 & 1,3 & 1,4 & 1,6 & 2,0 & 1,9 \\
\hline $\begin{array}{l}\text { Veteri- } \\
\text { nária }\end{array}$ & 3,5 & 2,2 & 1,9 & 1,9 & 1,7 & 1,7 & 1,4 & 1,4 & 1,5 & 1,5 & 1,8 & 2,3 & 2,2 \\
\hline $\begin{array}{l}\text { Odonto- } \\
\text { logia }\end{array}$ & 8,7 & 5,9 & 1,9 & 1,8 & 1,7 & 1,6 & 1,5 & 1,6 & 1,8 & 2,4 & 2,4 & 3,4 & 3,4 \\
\hline Medicina & 23,2 & 18,2 & 16,3 & 11,9 & 11,4 & 10,5 & 11,6 & 10,8 & 13,7 & 18,2 & 25,7 & 30,3 & 29,0 \\
\hline
\end{tabular}

Fonte: Elaboração própria com dados do Inep/ MEC e Sigras/ObservaRH - IMS/Uerj, 2013 e Inep, 2013.

Também é possível observar no Gráfico 4 que, apesar de o contingente de ingressantes ter ampliado significativamente durante o período, o número de concluintes não cresceu em ritmo semelhante, o que indica a presença de outro fenômeno - a evasão. A evasão consiste no abandono definitivo do curso pelo estudante antes de sua conclusão e gera significativas perdas econômicas e acadêmicas para as instituições de forma geral. É apontada como um problema para os sistemas de ensino superior em todo o mundo. No Brasil, este é um problema observado tanto nas IESs públicas quanto nas privadas, nestas últimas, em maior dimensão (Silva Filho et al., 2007). Estudo realizado sobre a evasão no Brasil entre 2000 e 2005 verificou que a média anual nas IESs privadas era de $26 \%$, maior que a em IESs públicas que, no mesmo período, era de 12\% (Silva Filho et al., 2007). O mesmo estudo identificou que o curso Medicina apresentou a menor de abandono anual médio entre todos os cursos, públicos ou privados, de apenas $4 \%$. 


\section{Ensino a distância em cursos da saúde}

No período analisado, os cursos de graduação por ensino a distância (EaD) apresentaram uma expansão significativa no Brasil e o setor privado foi responsável pela maior parte desse crescimento. O número de matrículas nesta modalidade de ensino passou de 49.911, no ano inicial deste período, para 1.573.573 em 2013, o que representou um crescimento de aproximadamente $3.000 \%$ (Inep, 2013). Em 2013, essa modalidade de ensino representava $16 \%$ do total de estudantes no ensino superior. Na área da saúde, também de acordo com dados do Inep, no ano de 2013, estavam em funcionamento cursos de Enfermagem, Educação Física e Serviço Social ${ }^{6}$ na modalidade a distância. Nos de Enfermagem e Educação Física, essa modalidade de ensino apresentou uma pequena proporção do total $(0,3 \%$ das de Enfermagem e 0,8\% de Educação Física). Em 2013, existiam duas instituições credenciadas para oferta de cursos de Enfermagem na modalidade a distância e uma para o de Educação Física, todas essas no setor privado.

Na graduação em Serviço Social, essa modalidade de ensino apresentou um percentual expressivo do total de matrículas. De acordo com informações do Sigras, em 2013, o total, em IESs públicas e privadas, em cursos de Serviço Social presenciais era de 79.163. De acordo com informações do Inep, nesse mesmo ano, existiam 95.595 alunos cursando essa graduação na modalidade $\mathrm{EaD}$, perfazendo $54,7 \%$ do total de matrículas, das quais $90 \%$ eram em IESs privadas. Em 2013, existiam 18 instituições credenciadas para a oferta de cursos de Serviço Social a distância, sendo 17 privadas e uma pública. Dados mais recentes indicam que a tendência à expansão dessa modalidade de ensino em alguns cursos da saúde se mantém. Consulta realizada em dezembro de 2015 no sistema e-MEC identificou que existiam cinco IESs privadas credenciadas para a oferta de cursos a distância de Enfermagem, três a mais que em 2013. Também constavam no sistema do e-MEC, cursos autorizados nesta modalidade de Biologia, Fisioterapia, Farmácia, Biomedicina e Nutrição. O que indica que está ocorrendo uma expansão dessa modalidade entre as formações para a saúde.

No Brasil, após a aprovação da Lei de Diretrizes e Bases da Educação Nacional e, sobretudo, após 2002, ocorreu uma intensificação da abertura e credenciamento de instituições de educação superior para a oferta de cursos EaD. Ainda que existam algumas ações direcionadas à efetivação de experiências de EaD no setor público, sendo a principal a Universidade Aberta do Brasil (UAB), tal processo assumiu importância, sobretudo, com a abertura de curso por IESs privadas.

Para o setor privado, a modalidade de ensino a distância representa a possibilidade de aumentar a capilaridade das instituições no país, devido a sua 
mensalidade mais baixa e à possibilidade de alcançar localidades isoladas, o que aumenta a demanda potencial por acesso ao ensino superior. Além disso, a oferta de cursos nessa modalidade propicia uma significativa redução de custos para as instituições ao permitir um maior número de estudantes por docente e reduzir a necessidade de salas de aula e a manutenção de grandes estruturas físicas (Sécca e Leal, 2009).

Embora as consequências da expansão de cursos EaD nas graduações em saúde ainda sejam pouco conhecidas, esse fenômeno coloca em questão uma série de controvérsias sobre a qualidade e as limitações de cursos nesses moldes, considerando as particularidades da formação dos profissionais da saúde, principalmente a necessidade de vivências práticas e do contato dos graduandos com a comunidade e os serviços de saúde (Pereira, 2009). Expressando essas contradições, em junho de 2016, o Conselho Nacional de Saúde publicou uma resolução na qual se posicionou contra a autorização de qualquer um dos 14 cursos de graduação em saúde na modalidade EaD (Conselho Nacional de Saúde, 2016).

\section{Considerações finais}

A configuração e o papel do ensino superior privado passaram por mudanças significativas nas últimas décadas, possivelmente influenciadas por mudanças no marco regulatório, pela adoção de políticas que propiciaram a expansão das IESs privadas assim como pela introdução de diversos mecanismos de mercado, como a concorrência entre instituições e a entrada e crescimento de grandes grupos econômicos. Assim como observado no ensino superior em geral, em muitos dos cursos da saúde, já no início da década de 1990, a maioria das matrículas era em IESs privadas. Desde 2003, observou-se uma tendência à desconcentração da oferta desses cursos, com crescimento da participação privada nas regiões Norte, Nordeste e Centro-Oeste. No início dos anos 2000, as tendências gerais do ensino privado nos cursos da saúde foram a redução das taxas de crescimento comparativamente às observadas na década de 1990, por uma desproporção entre o número de vagas ofertadas e a demanda por acesso, assim como pela expansão do número de cursos e matrículas na modalidade a distância em algumas graduações.

Ao analisarmos os cursos separadamente, foi possível observar que a dinâmica das IESs privadas é heterogênea entre as diferentes graduações em saúde. E ainda que, entre 2003 e 2013, o crescimento de matrículas, cursos e instituições tenha sido uma tendência quando analisamos os dados dos cursos de forma agregada, em alguns já se observa a tendência inversa, indicando que a expansão privada na formação de profissionais da saúde não é um fenômeno uniforme ou mesmo definitivo. 
No que diz respeito à retração do setor privado em alguns cursos, os achados deste trabalho são compatíveis com os apresentados por Levy (2013) em estudo sobre a redução do setor de ensino superior privado no mundo, no qual identificou que, apesar de a expansão ser tendência dominante do setor de ensino superior privado em nível global e na maior parte dos países, é possível distinguir casos de contração proporcional e/ou absoluta em alguns países, subsetores e cursos, mesmo em períodos de crescimento.

Como já mencionado, a participação do setor privado no curso de Medicina apresentou características peculiares quando comparado com os outros da área da saúde e com as tendências gerais do setor. Além de apresentar a maior relação candidato/vaga entre os cursos privados, as taxas de crescimento de cursos de Medicina privados foram bem menores do que a média nacional entre os anos de 1993 e 2004, período no qual o setor privado cresceu mais rapidamente. Podem ter contribuído para esse processo tanto a dificuldade para a entrada de novos cursos no mercado, mediante a necessidade de parecer favorável do Conselho Nacional de Saúde para a autorização da abertura de novos cursos, como o fato de que a graduação em medicina é um curso que envolve custos fixos altos e, como apontado na literatura, os cursos que apresentaram as maiores taxas de crescimento do setor privado na década de 1990 foram os mais baratos (Altbach, Reisberg e Rumbley, 2009; Sécca e Leal, 2009).

Os dados levantados e a análise empreendida neste trabalho permitem sugerir alguns desafios ao desenvolvimento de políticas direcionadas para ordenação da formação dos profissionais para a saúde, identificando questões importantes que devem ser incorporadas à agenda de pesquisa do setor. Em primeiro lugar, são necessárias pesquisas que analisem as relações entre a dinâmica do mercado de trabalho de profissionais da saúde e o mercado de ensino superior, incluindo pesquisas que busquem identificar em que medida as mudanças instituídas no mercado de trabalho, como a expansão expressiva de postos via Estratégia de Saúde da Família, impactaram no mercado de ensino superior. De acordo com McPake et al. (2015), as influências das forças de mercado sobre o processo de formação dos profissionais da saúde geralmente são ignoradas, o que resulta na formulação de políticas e mecanismos de regulação insuficientes.

Em segundo lugar, as IESs privadas lucrativas, de forma geral, apresentam características distintas das instituições não lucrativas e constituem o subsetor que apresentou as maiores taxas de crescimento nas últimas décadas (Salto, 2014). Apesar de esse aspecto ser extremamente importante para a análise da dinâmica do setor nos cursos da saúde, e poder representar importantes impactos para a formação na área da saúde, os dados oficiais divulgados pelo Inep não fazem distinção entre privadas lucrativas e não lucrativas na classificação jurídico-administrativa das IESs, o que representa uma importante limitação para a análise. 
A tendência de crescimento da modalidade a distância, apontada tanto na literatura consultada quanto nos dados levantados, também surge como um desafio para as políticas do setor que, tradicionalmente, são dirigidas para cursos presenciais. É fundamental que se mapeie as características e as condições dessa oferta.

Embora, neste trabalho, as IESs privadas tenham sido tratadas de forma geral, sabe-se que não se trata de um setor homogêneo e que, mesmo entre instituições que estão sob a mesma categoria jurídico-administrativa, existem importantes diferenças no que tange às atividades desenvolvidas, ao tamanho das instituições, perfil dos estudantes e corpo acadêmico, regimes de trabalho, modelos pedagógicos, modalidades de gestão e composição das fontes de financiamento (Dias Sobrinho, 2013). Essas diferenças impactam na relação com a sociedade e com o Estado e, consequentemente, na formação dos profissionais da saúde. Portanto, também é necessária a realização de estudos de caso sobre o papel dos diferentes tipos de instituições privadas.

Também precisam ser mais bem investigados aspectos relacionados às características e informações sobre a propriedade das IESs que mantêm cursos da saúde. Neste trabalho, não foi investigada a participação dos grandes grupos educacionais de capital aberto nas diferentes graduações em saúde, ainda que o crescimento dessas instituições por processos de aquisição e fusão tenha sido apontado pela literatura consultada como uma das principais tendências para o ensino superior no país. Por fim, as reduções no número de matrículas e cursos, como as observadas nos cursos de Terapia Ocupacional, Fonoaudiologia e Biologia, devem ser analisadas para compreender quais os possíveis impactos desse encolhimento no mercado de trabalho e no sistema de saúde.

A expansão do setor privado no ensino superior não representa apenas a simples transferência do financiamento do ensino do Estado para os alunos e família, mas envolve mudanças mais profundas no formato e no funcionamento das instituições e no papel do Estado. A expansão do número de vagas e matrículas em cursos da saúde reconfigura o mercado de trabalho na área, porém, não necessariamente soluciona problemas como a desigualdade da distribuição de profissionais entre as regiões e a dificuldade de fixação em determinadas áreas (Dal Poz, Pierantoni e Sábado, 2013). Em vez disso, pode até causar desequilíbrios entre oferta e demanda e ter como uma de suas consequências a diminuição da remuneração de algumas categorias (Haddad et al., 2010).

A formação superior ocupa um papel estratégico para o desenvolvimento econômico e social do país, uma vez que a melhoria dos níveis de escolaridade da população e a produção de conhecimentos no âmbito das IESs podem gerar benefícios que extrapolam os limites individuais, e aí está o caráter de bem público do ensino superior (Corbucci, 2007). Nesse sentido, a formação 
dos profissionais da saúde desempenha um papel duplamente importante, pois, além de representar os benefícios sociais envolvidos no ensino superior de forma geral, também é central para o setor, com importantes consequências para o sistema de saúde. Nessa perspectiva, a expansão e a consolidação da atuação de IESs privadas na formação dos profissionais da saúde impõem novos desafios para os quais são requeridas intervenções estatais que compatibilizem o perfil, o número e a distribuição dos profissionais para garantir a estruturação do sistema de saúde e o direito universal à saúde.

\section{Colaboradores}

Thais de Andrade Vidaurre Franco realizou o planejamento, desenvolvimento, execução da pesquisa, elaboração e revisão do artigo. Mario Roberto Dal Poz orientou o processo de planejamento e a realização da pesquisa e participou da elaboração e revisão do artigo. Os autores declaram não haver conflitos de interesses.

Resumen La enseñanza superior brasileña, históricamente, está marcado por la presencia de instituciones privadas. Durante la gran expansión producida en las últimas dos décadas el sector privado presentó un crecimiento en el número de matrículas y en el porcentaje de participación. Este artículo describe la participación privada en las titulaciones en salud en el período entre 1993 y 2013. La revisión bibliográfica sobre la enseñanza superior brasileña y el análisis descriptivo de datos secundarios ponen de manifiesto que la participación del sector privado en la formación en salud, en muchos aspectos, ha sido compatible con la dinámica del sector de enseñanza superior. En la década de 1990, el crecimiento del sector privado fue una tendencia en todas las licenciaturas en salud y en la mayor parte de las carreras las tasas de crecimiento fueron mayores que el promedio nacional. En el período entre 2003 y 2013, las carreras de Medicina, Odontología y Servicio Social presentaron tasas de crecimiento mayores que en el período anterior y las restantes presentaron una desaceleración de las tasas de crecimiento; ya en las carreras de Biología, Fonoaudiología y Terapia Ocupacional, se observó una reducción del número de matrículas en instituciones privadas.

Palavras clave instituciones de enseñanza superior; sector privado; recursos humanos en salud; educación superior. 


\section{Notas}

${ }^{1}$ Universidade Estácio de Sá, Rio de Janeiro, RJ, Brasil.

Correspondência:CorreaDutra,37, apartamento402,Flamengo,CEP22210-050,RiodeJaneiro,RJ,Brasil. $<$ thais.a.v.franco@gmail.com>

${ }^{2}$ Universidade do Estado do Rio de Janeiro, Instituto de MedicinaSocial, Rio de Janeiro, RJ, Brasil. <dalpozm@uerj.br>

${ }^{3}$ Porcentagem ou grau de participação de uma empresa ou setor em determinado mercado.

${ }^{4} \mathrm{O}$ primeiro curso de Biomedicina privado, de acordo com dados do Inep data de 1998, logo, as informações apresentadas aqui para esse curso são referentes ano de 1998, e não de 1993.

${ }^{5}$ De acordo com dados do Inep, o primeiro curso de Biomedicina privado foi aberto em 1998, com um total de 60 alunos matriculados. De 1998 até 2003 foram criados mais 26 cursos de Biomedicina privados. O fato de o curso ter sido criado nessa década, de certa forma, justifica a diferença da sua variação de crescimento com relação aos outros cursos da saúde.

\section{Referências}

ALTBACH, Philip G.; REISBERG, Liz; RUMBLEY, Laura E. Trends in global higher education: tracking an academic revolution. Paris: United Nations Educational, Scientific and Cultural Organization (Unesco), 2009. Disponível em: <http://atepie.cep.edu.rs/public/ Altbach,_Reisberg,_Rumbley_Tracking_an_ Academic_Revolution,_UNESCO_2009.pdf > . Acesso em: 24 set. 2015.

CARVALHO, Cristina H. A. A mercantilização da educação superior brasileira e as estratégias de mercado das instituições lucrativas. Revista Brasileira de Educação, Rio de Janeiro, v. 18, n. 54, p. 761-801, jul. 2013.

CONSELHO NACIONAL DE SAÚDE. Resolução n. 515, de 7 de outubro. Disponível em: <http://conselho.saude.gov.br/resolucoes/2016/ Reso515.pdf $>$. Acesso em: 5 jun. 2016.

CORBUCCI, Paulo R. Desafios da educação superior e desenvolvimento no Brasil. Texto para discussão n. 1287. Brasília, DF: Ipea, jul. 2007. Disponível em: <http://ipea.gov. br/agencia/images/stories/PDFs/TDs/td_1287. pdf $>$. Acesso em: 30 set. 2015.
CORBUCCI, Paulo R. Evolução do acesso de jovens à educação superior no Brasil. Texto para discussão n. 1950. Brasília, DF: Ipea, 2014. Disponível em: <http://www.ipea. gov.br/portal/index.php?option $=\mathrm{com}_{-}$ content $\&$ view $=$ article $\& i d=22089>$. Acesso em: 30 set. 2015 .

DAL POZ, Mario R.; PIERANTONI, Célia R.; SÁBADO, Girardi. Formação, mercado de trabalho e regulação da força de trabalho em saúde no Brasil. In: FUNDAÇÃO OSWALDO CRUZ. A saúde no Brasil em 2030: diretrizes para a prospecção estratégica do sistema de saúde brasileiro. Rio de Janeiro: Fundação Oswaldo Cruz/Ipea, 2013. p. 184-233. Volume 3.

DAL POZ, Mario R.; SCHEFFER, Mario. The privatization of medical education in Brazil: trends and challenges. Human Resources for Health, London, v. 13, n. 1, p. 96, dez. 2015.

DIAS SOBRINHO, José. Educação superior: bem público, equidade e democratização. Avaliação: revista da avaliação da educação superior (Campinas), São Paulo, v. 18, n. 1, p. 107-126, mar. 2013. 
DURHAM, Eunice R. O ensino superior no Brasil: público e privado. Núcleo de Pesquisas sobre Ensino Superior da Universidade de São Paulo. 3 nov. 2003. Disponível em: <http:// nupps.usp.br/downloads/docs/dt0303.pdf >. Acesso em: 7 jan. 2014.

FÁVERO, Maria L. A.; SGUISSARDI, Valdemar. Quantidade/qualidade e educação superior. Revista Educação em Questão, Natal, v. 42, n. 28, p. $61-88$, abr. 2012.

HADDAD, Ana Estela et al. Formação de profissionais de saúde no Brasil: uma análise no período de 1991 a 2008. Revista de Saúde Pública, São Paulo, v. 44, n. 3, p. 383-393, jun. 2010.

INEP (Instituto Nacional de Estudos e Pesquisas Educacionais Anísio Teixeira). Sinopses estatísticas da educação superior. 2013. Disponível em: <http://portal.inep.gov.br/ superior-censosuperior-sinopse $>$. Acesso em: 1 out. 2015.

LEVY, Daniel C. The decline of private higher education. Higher Education Policy, [s.l.], v. 26, n. 1, p. 25-42, 2013.

MANCEBO, Deise; VALE, Andréa A. Expansão da educação superior no Brasil e a hegemonia privado-mercantil: o caso da Unesa. Educação \& Sociedade, Campinas, v. 34, n. 122, p. 81-98, mar. 2013.

MARTINS, Carlos B. A participação das instituições privadas na reconfiguração do ensino superior no Brasil. Análise Social, Lisboa, v. 208, n. 3, p. 622-658, jul. 2013.

MCPAKE, Barbara et al. The economics of health professional education and careers: insights from a literature review. The World Bank, 2015. Disponível em: <http://elibrary.worldbank. org/doi/book/10.1596/978-1-4648-0616-2>. Acesso em: 16 out. 2016.

PEREIRA, Larissa D. Mercantilização do ensino superior, educação a distância e Serviço Social. Revista Katálysis, Florianópolis, v. 12, n. 2, p. 268-277, dez. 2009.
PIERANTONI, Célia R. et al. Graduações em saúde no Brasil: 2000-2010. Rio de Janeiro: Cepesc, IMS/Uerj, ObservaRH, 2012. Disponível em: <http://www.obsnetims.org. br/uploaded/6_10_2014_1_livro_graduacoes_em_saude.pdf $>$. Acesso: 16 out. 2016.

Rede Observatório de Recursos Humanos em Saúde (Observa RH). Estação de Trabalho Instituto de Medicina Social da Universidade do Estado do Rio de Janeiro. Sistema de Indicadores das Graduações em saúde (Sigras). 2013. Disponível em: $<$ http://www.obsnetims.org. br/sigras $>$. Acesso em: 7 mar. 2016.

REZENDE, Mônica. A articulação educaçãosaúde (AES) no processo de formulação das politicas nacionais voltadas para a formação de nivel superior dos profissionais de saúde. 2013. 213 f. Tese (Doutorado em Ciências na área de Saúde Pública) - Escola Nacional de Saúde Pública Sergio Arouca, Rio de Janeiro, 2013. Disponível em: < http://www.arca.fiocruz.br/ handle/icict/7674>. Acesso em: 2 dez. 2014.

SALTO, Dante J. Brazil: a for-profit giant. International Higher Education, [s.1.], n. 74, p. 21-22, abr. 2014.

SCHWARTZMAN, Jacques; SCHWARTZMAN, Simon. O ensino superior privado como setor econômico. Avaliação de políticas públicas em Educação, Rio de Janeiro, v. 10, p. 411-440, 2002.

SÉCCA, Rodrigo X.; LEAL, Rodrigo M. Análise do setor de ensino superior privado no Brasil. BNDES Setorial, Rio de Janeiro, $\mathrm{n}$. 30, p. 103-156, 2009.

SGUISSARDI, Valdemar. Regulação estatal e desafios da expansão mercantil da educação superior. Educação \& Sociedade, Campinas, v. 34, n. 124, p. 943-960, set. 2013.

SILVA FILHO, Roberto L. L. et al. A evasão no ensino superior brasileiro. Cadernos de Pesquisa, São Paulo, v. 37, n. 132, p. 641659, dez. 2007. 
SINDICATO DAS MANTENEDORAS DE ENSINO SUPERIOR (SEMESP). Mapa do Ensino Superior no Brasil. São Paulo: SEMESP, 2015. Disponível em: <http://convergenciacom.net/ pdf/mapa-ensino-superior-brasil-2015.pdf $>$. Acesso em: 12 mar. 2015.

STROMQUIST, Nelly P. Educação latino-americana em tempos globalizados. Sociologias, Porto Alegre, v. 14, n. 29, p. 72-99, abr. 2012.

TANEGUTI, Luiza Y. Relatório técnico contendo estudo sobre a atual relação oferta/demanda de cursos de graduação no Brasil, como subsídio ao Conselho Nacional de Educação para a formulação de politicas públicas que possibilitem a melhor distribuição da oferta de vagas no ensino superior de graduação. Brasília: Ministério da Educação, 2013.

TUON, Ligia. Valor da Kroton na bolsa salta nove posições após compra da Anhanguera. Valor Econômico, São Paulo, 7 abr. 2014. Disponível em: <http://www.valor.com.br/empresas/3604836/valor-da-kroton-na-bolsa-saltanove-posicoes-apos-compra-da-anhanguera $>$. Acesso em: 4 maio 2015.

Recebido em 24/10/2016.

Aprovado em 23/08/2017. 